\title{
Function of the photosynthetic apparatus of oilseed winter rape under elicitation by Phoma lingam phytotoxins in relation to carotenoid and phenolic levels
}

\author{
Katarzyna Hura • Tomasz Hura • Maciej Grzesiak
}

Received: 30 April 2013/Revised: 11 September 2013/Accepted: 8 October 2013/Published online: 22 October 2013

(C) The Author(s) 2013. This article is published with open access at Springerlink.com

\begin{abstract}
Stem canker (blackleg) caused by fungus Leptosphaeria maculans/L. biglobosa is one of the most damaging diseases of oilseed winter rape crops. Some winter oilseed rape varieties (Brassica napus L. var. oleifera 'Bojan', 'Lisek', 'Liclassic') that differ in blackleg resistance have been chosen for the experiment. In all tested cultivars during growth on a medium with a fungal elicitor, a distinct reduction in the length of the stems, the roots and the entire length of the seedlings was observed. However, only in the case of the 'Liclassic' cultivar, fresh and dry weight were reversibly affected during elicitation. The cultivar 'Liclassic', recognized as blackleg mildly resistant, was characterized by the most efficient photosynthetic apparatus under toxin elicitation. The efficient adaptation of photosynthetic apparatus in this cultivar was accompanied by an increase in the content of phenolics, chlorophyll and carotenoids. Only for 'Liclassic', did most of the measured parameters of chlorophyll fluorescence $\left(F_{\mathrm{v}}{ }^{\prime} / F_{\mathrm{m}}{ }^{\prime}, \Phi_{\mathrm{PSII}}, q_{\mathrm{P}}\right.$ and $\left.q_{\mathrm{N}}\right)$ exhibit a statistically significant correlation with regard to the level of carotenoids. Therefore, in'Liclassic', the observed increase in carotenoid content seems to be a significant biochemical factor which can raise the efficiency of the photosynthetic apparatus under elicitation by Phoma lingam toxins.
\end{abstract}

Communicated by U. Feller.

K. Hura $(\square)$

Department of Plant Physiology, Faculty of Agriculture and

Economics, Agricultural University, Podłużna 3, 30-239

Kraków, Poland

e-mail: rrhura@cyf-kr.edu.pl

T. Hura $\cdot$ M. Grzesiak

Polish Academy of Sciences, The Franciszek Górski Institute of

Plant Physiology, Niezapominajek 21, 30-239 Kraków, Poland
Keywords Carotenoids - Chlorophyll fluorescence · Leptosphaeria maculans/L. biglobosa . Winter rape

\section{Introduction}

Leptosphaeria maculans (Desm.) Ces. et de Not [imperfect stage: Phoma lingam (Tode ex Fr.) Desm.] and L. biglobosa cause the blackleg (stem canker) disease attacking oilseed winter rape in agricultural areas around the world (West et al. 2001). The symptoms of the disease are widely described in the relevant subject literature (Gladders and Musa 1980; Jędryczka et al. 1994). Likewise, it has been established that strains of L. maculans/L. biglobosa are variable, i.e. in pathogenicity (Jędryczka et al. 1994, 1997; Kachlicki and Jędryczka 1994). Several previous studies have shown that the severity of an epidemic can differ significantly between years, regions, varieties and also within a variety of oilseed winter rape (Brun et al. 2010; Jędryczka et al. 2010; Dawidziuk et al. 2012; Kaczmarek et al. 2012). The risk of crop production loss due to unpredictability in the level and consequence of blackleg disease is very high (West et al. 2001). Therefore, improving the plant resistance is a key issue. A serious obstacle to achieve such goal is that visible symptoms of blackleg are not frequently observed in autumn but in the late spring.

Chlorophyll fluorescence imaging is commonly used to detect stress in plants by monitoring changes in photosynthetic efficiency. Moreover, this method may reveal subtle differences between and within genotypes under abiotic and biotic stresses (Buschmann and Lichtenthaler 1998; Buschmann et al. 2000; Plazek et al. 2004). Measurements of chlorophyll fluorescence 
imaging allow estimating the photochemical efficiency of photosystem II, the effectiveness of utilization of excitation energy in the photosynthesis process, the level of openness of reaction centres and the amount of energy reaching the photosynthetic apparatus, that is released as heat (Baker and Rosenqvist 2004). In addition, it has been shown that some chlorophyll fluorescence parameters are suitable for aiding the estimation of the leaf photosynthetic $\mathrm{CO}_{2}$ assimilation rate and leaf photosynthetic performance (Fracheboud and Leipner 2003). The levels of chlorophyll and carotenoids are directly involved in the photosynthetic apparatus activity and can induce modifications in values of chlorophyll fluorescence parameters (Havaux et al. 2000). Carotenoids participate in the photoprotection of the photosynthetic apparatus by neutralizing triplet chlorophyll and reactive oxygen species (Telfer 2005).

Another example of biochemically active substances is plant phenolics, which are effective photoprotectors and scavengers of reactive oxygen species that may not directly increase the activity of the photosynthetic apparatus and photosynthetic carbon metabolism (Blokhina et al. 2003). It is well known that phenolics are also classified as phytoalexins. These are antimicrobial compounds accumulated in the plant cells in response to pathogen attack. The accumulation of phenolics in the cell walls is accompanied by an increase in lignifications (Płażek et al. 2005). An increase in cell wall phenolics as a consequence of pathogen attack was also reported (De Ascensao and Dubery 2003). Moreover, the phenolic compounds as photoprotectors limit the chlorophyll excitation during unfavourable conditions for the photosynthetic apparatus. Plant phenolics can transform high energy radiation (e.g. UV) into radiation (blue-green fluorescence) with a lower destructive potential to the photosynthetic apparatus (Hura et al. 2010). Although, the role of phenolic compounds in biotic stresses is well developed, little is known about chlorophyll and carotenoids involvement in the photosynthetic apparatus adaptation under pathogen infection. In particular, carotenoids within the photosynthetic apparatus can support the neutralization of the excitation energy, as well as reactive oxygen species as a response to pathogen toxins.

The aim of the experiments was to detect perturbations in the activity of the photosynthetic apparatus, in seedlings of oilseed winter rape differing in blackleg resistance on the basis of chlorophyll fluorescence imaging measurements and in relation to the chlorophyll, carotenoid and phenolic content. It is possible to assume that the photosynthetic apparatus of oilseed winter rape varieties, possessing high levels of both carotenoids and phenolics, will be more resistant to pathogen phytotoxins.

\section{Materials and methods}

Plants material and Phoma lingam infection

Some winter oilseed rape varieties (Brassica napus L. var. oleifera 'Bojan', 'Lisek', 'Liclassic') that differ in blackleg resistance have been chosen for the experiment. Seeds were obtained from Plant Breeding Strzelce Ltd., Poland. Based on field trials in Polish conditions, breeding observation and our experiments concerning the antioxidative potential of these varieties (data not shown), 'Liclassic' and 'Lisek' in contrast to 'Bojan' (susceptible to blackleg disease) have been found to be mildly resistant to blackleg disease. Seeds were surface sterilized in a $5 \%(\mathrm{v} / \mathrm{v})$ 'Domestos' bleach solution (Lever Bydgoszcz, Poland) for $20 \mathrm{~min}$ and then washed three times with distilled water. Seeds until germination were placed on the agar medium (Murashige and Skoog 1962). Plants were grown under a $12-\mathrm{h}$ photoperiod at $20 / 20{ }^{\circ} \mathrm{C}$ (day/night) for 11 days. The level of photosynthetic photon flux density (PPFD) at the plant's tip was about $150 \mu \mathrm{mol} \mathrm{m} \mathrm{m}^{-2} \mathrm{~s}^{-1}$.

After 3 days, half of the seeds were transferred to a new agar medium. The second part of the germinating seeds was placed on the agar medium containing a toxic culture of filtrates of isolate Raw4 belonging to Tox ${ }^{+}$(Jędryczka et al. 1997), produced by Phoma lingam in the ratio of 1:4 (filtrate/agar medium). The final spore concentration was adjusted to $1 \times 10^{7}$ per $1 \mathrm{ml}$. Metabolites of Raw4 isolate were obtained from liquid cultures of the fungus as described by Jęryczka et al. (1991). All the above-mentioned operations have been completed under a laminar flow chamber in sterile conditions.

\section{Sampling}

Sampling and measurements were performed during 4, 7, and 11th day of seedlings growth on an agar medium containing a toxic culture of $L$. maculans/L. biglobosa filtrates. All analyses were performed on seedlings of winter rape being in the two-cotyledon phase during the whole experiment.

\section{Chlorophyll fluorescence}

Measurements of chlorophyll fluorescence parameters were taken with the use of a PSI Fluorcam 700MF chlorophyll fluorescence imaging system (PSI, Brno, Czech Republic) and according to Nedbal et al. (2000). Fluorcam v. 3.5 software was applied to adjust the imaging system. Seedlings were dark adapted for $20 \mathrm{~min}$ to estimate the maximum photochemical efficiency $\left(F_{\mathrm{v}} / F_{\mathrm{m}}\right)$ of PSII. After seedling illumination, the efficiency of excitation transfer to open PSII centres $\left(F_{\mathrm{v}}{ }^{\prime} / F_{\mathrm{m}}{ }^{\prime}\right)$, the photochemical 
quenching coefficient $\left(q_{\mathrm{P}}\right)$, the PSII quantum efficiency $\left(\Phi_{\mathrm{PSII}}\right)$, non-photochemical quenching coefficient $\left(q_{\mathrm{N}}\right)$ and the chlorophyll fluorescence decreasing ratio $\left(R_{\mathrm{Fd}}\right)$ were measured and calculated as described by Wingler et al. (2004). For each growing seedling, data were averaged for both cotyledons. Measurement was performed in ten replicates for each cultivar within the treatments.

\section{Chlorophyll and carotenoid content}

Leaf tissue was homogenized in $96 \%$ ethanol. The homogenate was centrifuged at $13,000 \mathrm{rpm}$ for $10 \mathrm{~min}$ at $+20{ }^{\circ} \mathrm{C}$. The total chlorophyll content was analysed spectrophotometrically (Ultrospec II, Biochrom, Cambridge, England). Absorbances at 663, 646 and $470 \mathrm{~nm}$ were read and the concentration of chlorophyll and carotenoid was then calculated as described by Lichtenthaler and Wellburn (1983). Analysis of chlorophyll and carotenoids was completed in seven replicates for each measurement point within the treatment.

\section{Phenolic content}

The total concentration of soluble phenolics was determined using the Folin-Ciocalteau method described by Singleton and Rossi (1965). Leaf tissue was homogenized in $80 \%$ ethanol. The homogenate was centrifuged at $13,000 \mathrm{rpm}$ for $15 \mathrm{~min}$ at $+4{ }^{\circ} \mathrm{C}$. The obtained supernatant was added at the amount of $0.1 \mathrm{ml}$ to the measurement solution containing $0.9 \mathrm{ml}$ of distilled water, $0.5 \mathrm{ml}$ of $25 \% \mathrm{Na}_{2} \mathrm{CO}_{3}$ and $0.125 \mathrm{ml}$ of Folin-Ciocalteau reagent (previously diluted 2-fold with distilled water). The absorbance was measured at $760 \mathrm{~nm}$. Chlorogenic acid was used as a standard. The estimation of total phenolics was made in seven replicates for each measurement point within the treatments.

Estimation of seedlings fresh/dry weight and morphological traits

Measurements of fresh and dry weight, as well as the length of the stem and the root of seedlings, were performed for each cultivar in ten replicates.

\section{Statistical analysis}

Statistica 9.0 software for Windows was used. Data presented in the figures are the mean \pm SE. Data were analysed using Student's $t$ test at $P=0.05$. Statistically significant differences are denoted by asterisks in the figures, in relation to the control plants. Correlations between analysed parameters were estimated at a probability of $P<0.05$ and only statistically significant correlations are presented in the figures.

\section{Results}

Chlorophyll fluorescence

Chlorophyll fluorescence measurements showed a varied pattern of changes in photosynthetic apparatus activity in oilseed winter rape cultivars, in a medium supplemented with fungal elicitor (Fig. 1). The least-changed parameter was the maximum photochemical efficiency of PSII $\left(F_{\mathrm{v}} /\right.$ $\left.F_{\mathrm{m}}\right)$, because changes to this parameter were for all cultivars similar in character. Four days after infection, rape seedlings showed a decrease in the maximum photochemical efficiency of PSII, whilst on the 7 and 11th day of growth an increase in $F_{\mathrm{v}} / F_{\mathrm{m}}$ values. Statistically significant differences as compared to the control were noted on the 4th day for the 'Liclassic' and 'Lisek' cultivars, on the 7th day for 'Bojan' and 'Lisek' and on the 11th day for all cultivars.

It should be stressed that the seedlings of three tested cultivars, on the 11th day of growth in the medium supplemented with the elicitor, were characterized by a higher values of $F_{\mathrm{v}} / F_{\mathrm{m}}$ in comparison to the control.

A statistically significant decrease in values of the $F_{\mathrm{v}}{ }^{\prime} /$ $F_{\mathrm{m}}{ }^{\prime}$ parameter, relating to the efficiency of light trapping by PSII antennas, was noted on the 4th day for 'Liclassic' and 'Lisek', whereas for the 'Liclassic' cultivar on the 7 th day, the $F_{\mathrm{v}}{ }^{\prime} / F_{\mathrm{m}}{ }^{\prime}$ values were significantly lower compared to the control (Fig. 1). In 'Bojan' seedlings, a statistically significant decrease in efficiency of light trapping by PSII antennas on the medium containing elicitor was shown on the 11th day. On the same day, values of $F_{\mathrm{v}}{ }^{\prime} / F_{\mathrm{m}}{ }^{\prime}$ for 'Liclassic' were significantly higher than the ones observed in the control plants.

Changes in PSII quantum efficiency $\left(\Phi_{\text {PSII }}\right)$ and also in fluorescence photochemical quenching $\left(q_{\mathrm{P}}\right)$ displayed a similar pattern within the tested cultivar (Fig. 1). For the 'Bojan' cultivar, a statistically significant decrease in $\Phi_{\text {PSII }}$ values occurred on the 11th day, and in case of $q_{\mathrm{P}}$ on the 7 and 11th day of growth on the medium supplemented with elicitor. The 'Liclassic' cultivar was characterized by the lowest values of $\Phi_{\text {PSII }}$ and $q_{\mathrm{P}}$ on 7 th day, but on 11th day there was a substantial and significant increase in the values of both parameters above the values obtained for the control.

Only in the case of 'Lisek', on the 4th day, was a statistically significant increase in values of $\Phi_{\mathrm{PSII}}$ and $q_{\mathrm{P}}$ parameters noted compared to the control, and afterwards, on the 7 and 11th day, there was a gradual decrease in values of both parameters. The $\Phi_{\mathrm{PSII}}$ and $q_{\mathrm{P}}$ values for the 'Lisek' cultivar were between the values obtained on the 11 day for 'Bojan' and 'Liclasssic'.

Statistically significant changes in values of the nonphotochemical fluorescence quenching coefficient $\left(q_{\mathrm{N}}\right)$ 
Fig. 1 Changes in $F_{\mathrm{v}} / F_{\mathrm{m}}$ (the maximum photochemical efficiency), $F_{\mathrm{v}}{ }^{\prime} / F_{\mathrm{m}}$ ' (the efficiency of excitation transfer to open PSII centres), $\Phi_{\text {PSII }}$ (PSII quantum efficiency), $q_{\mathrm{P}}$ (photochemical quenching coefficient) and $q_{\mathrm{N}}$ (nonphotochemical quenching coefficient) for seedlings of winter rape cultivars ('Bojan', 'Liclassic', 'Lisek') observed for 4, 7 and 11 days after elicitation. Each point represents the mean \pm standard error. $C$ represents the mean for total measurements performed in parallel for 4, 7 and 11 days on non-infected plants.

${ }^{*} P<0.05$ vs. control, Student's $t$ test

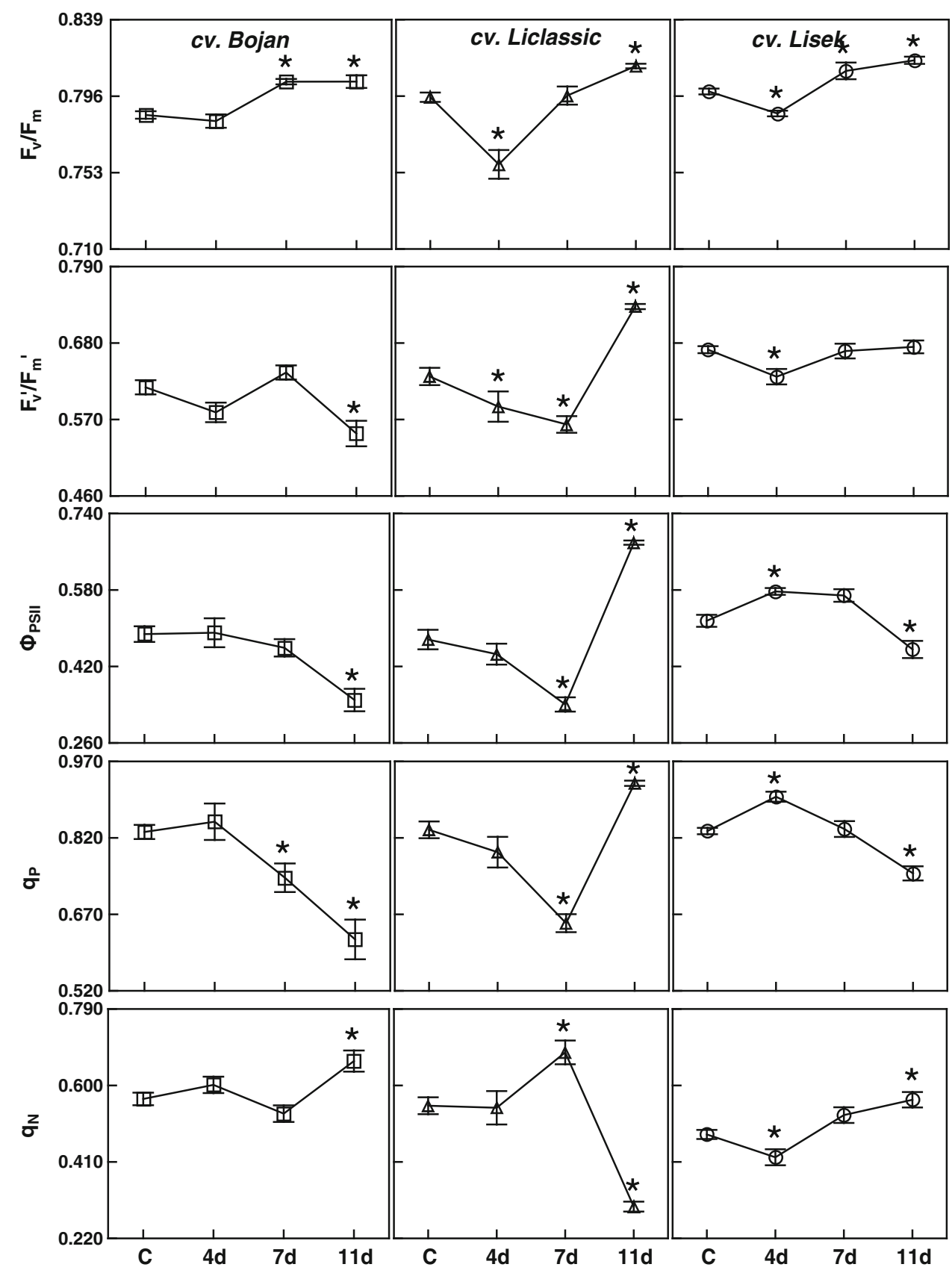

were observed on the 11th day in 'Bojan', on the 7 and 11 th day in 'Liclassic' and on the 4 and 11th day in 'Lisek' (Fig. 1). It should be noted that only on the 4th day for 'Lisek' and on the 11th day for 'Liclassic', was a statistically significant decrease in the value of $q_{\mathrm{N}}$ noted as compared to the control.

On the 4th day for 'Liclassic' and 'Lisek', a statistically significant decrease in values of the PSII vitality index $\left(R_{\mathrm{Fd}}\right)$, as compared to the control (Fig. 2) was noted. While for the 'Bojan' cultivar, a decrease in the value of $R_{\mathrm{Fd}}$ was observed on the 7 and 11th day. For 'Liclassic' and 'Lisek' on the 7 and 11th day of growth on the medium containing elicitor, the $R_{\mathrm{Fd}}$ values were about the same as those of the control.

Chlorophyll and carotenoid content

Only for the 'Lisek' cultivar, we observed a decrease in chlorophyll content on the 4, 7 and 11th day, compared to the control (Fig. 3). 'Bojan' showed a lower chlorophyll content on the 4 and 7th day, while for the 'Liclassic' cultivar only on the 4th day of seedlings growth on the medium containing a fungal elicitor. For 'Liclassic', on the 7 and 11th day, we noted a statistically significant higher 


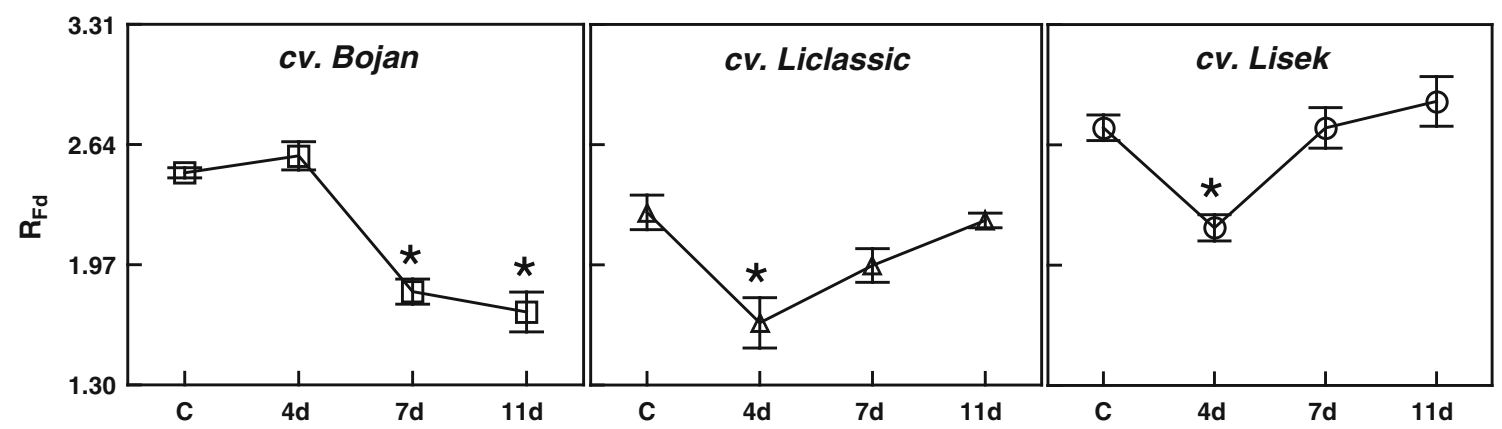

Fig. 2 Changes in $R_{\mathrm{fd}}$ (the vitality index of the photosynthetic apparatus) for seedlings of winter rape cultivars ('Bojan', 'Liclassic', 'Lisek') observed for 4, 7 and 11 days after elicitation. Each point represents the mean \pm standard error. $C$ represents the mean for total measurements performed in parallel for 4,7 and 11 days on noninfected plants. $* P<0.05$ vs. control, Student's $t$ test

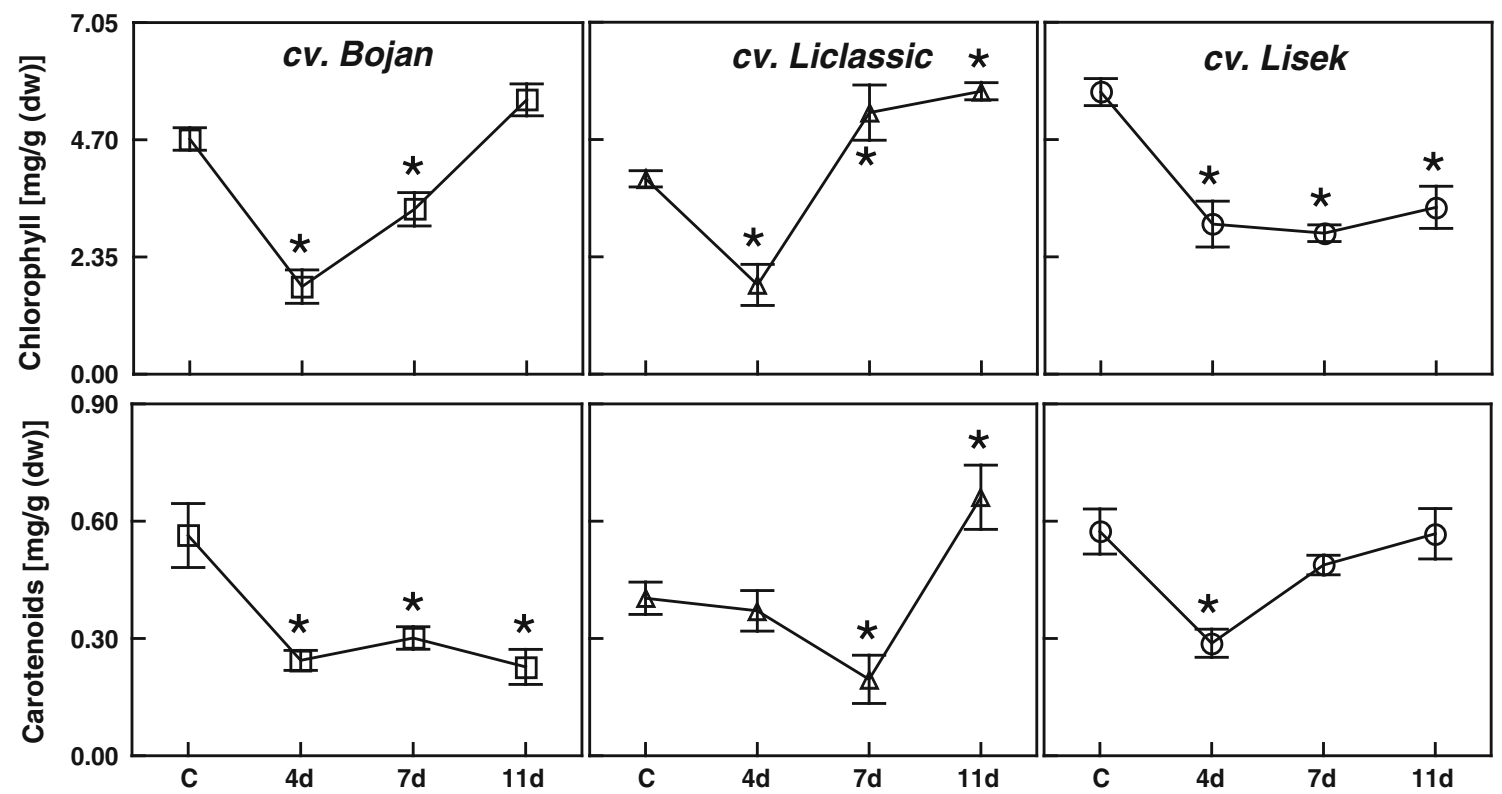

Fig. 3 Changes in chlorophyll and carotenoid content for seedlings of winter rape cultivars ('Bojan', 'Liclassic', 'Lisek') observed for 4, 7 and 11 days after elicitation. Each point represents the

level of chlorophyll than in the control, whereas for 'Bojan' the chlorophyll content was similar to the seedlings grown on the medium without the elicitor.

A reduced carotenoid content was observed for 'Bojan' on the 4 and 11th day, in 'Liclassic' on the 7th day, and in 'Lisek' on the 4th day of growth on the medium with the elicitor (Fig. 3). Similarly, as for chlorophyll, a higher level was found in 'Liclassic' than in the control group of carotenoids on the 11th day of seedlings growth, on the medium with the elicitor.

The content of phenolic compounds

The 'Bojan' cultivar displayed, on the 4 and 7th day of growth, on the medium containing fungal toxin, similar mean \pm standard error. $C$ represents the mean for total measurements performed in parallel for 4, 7 and 11 days on non-infected plants. $* P<0.05$ vs. control, Student's $t$ test

results to the control level of the total phenolic compounds (Fig. 4). A statistically significant increase in the content of phenolic compounds was observed in 'Bojan' on the 11th day. For 'Liclassic', a significant increase in phenolic content occurred on the 7 and 11th day, and for 'Lisek' on the 4 and 7th day. For the 'Lisek' cultivar, the phenolic content was similar to the control plants on the 11th day of growth on the medium with elicitor.

Seedlings fresh and dry weight, morphological traits

Changes in fresh and dry weight displayed a similar course within each cultivar (Fig. 5). A statistically significant decrease in fresh and dry weight of the 'Bojan' seedlings occurred on the 4, 7 and 11th day, and in 'Liclassic' on the 


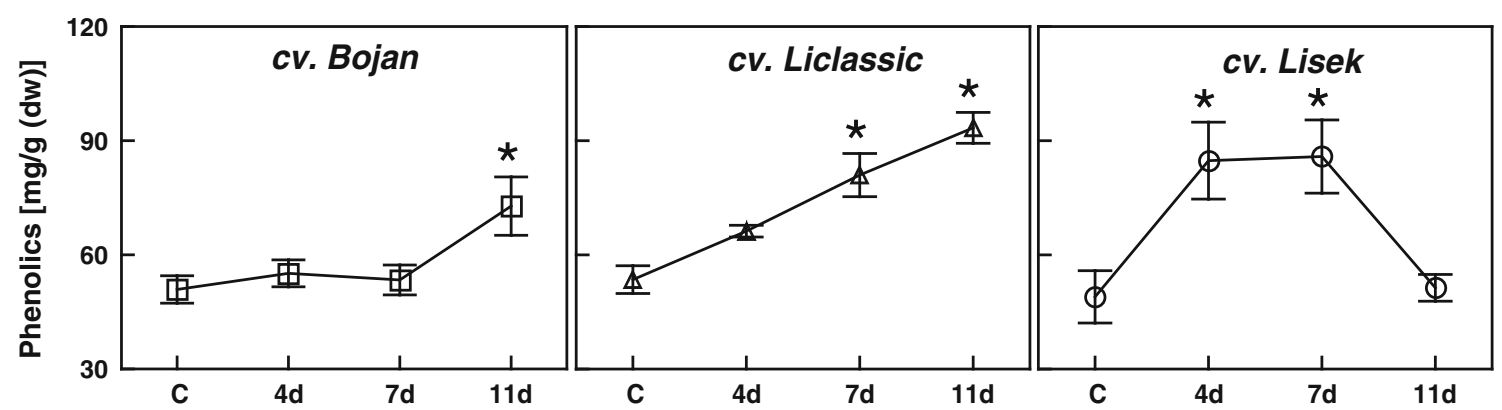

Fig. 4 Changes in total pool of phenolic content for seedlings of winter rape cultivars ('Bojan, 'Liclassic', 'Lisek') observed for 4, 7 and 11 days after elicitation. Each point represents the mean \pm standard error. $C$ represents the mean for total measurements performed in parallel for 4,7 and 11 days on non-infected plants. $* P<0.05$ vs. control, Student's $t$ test

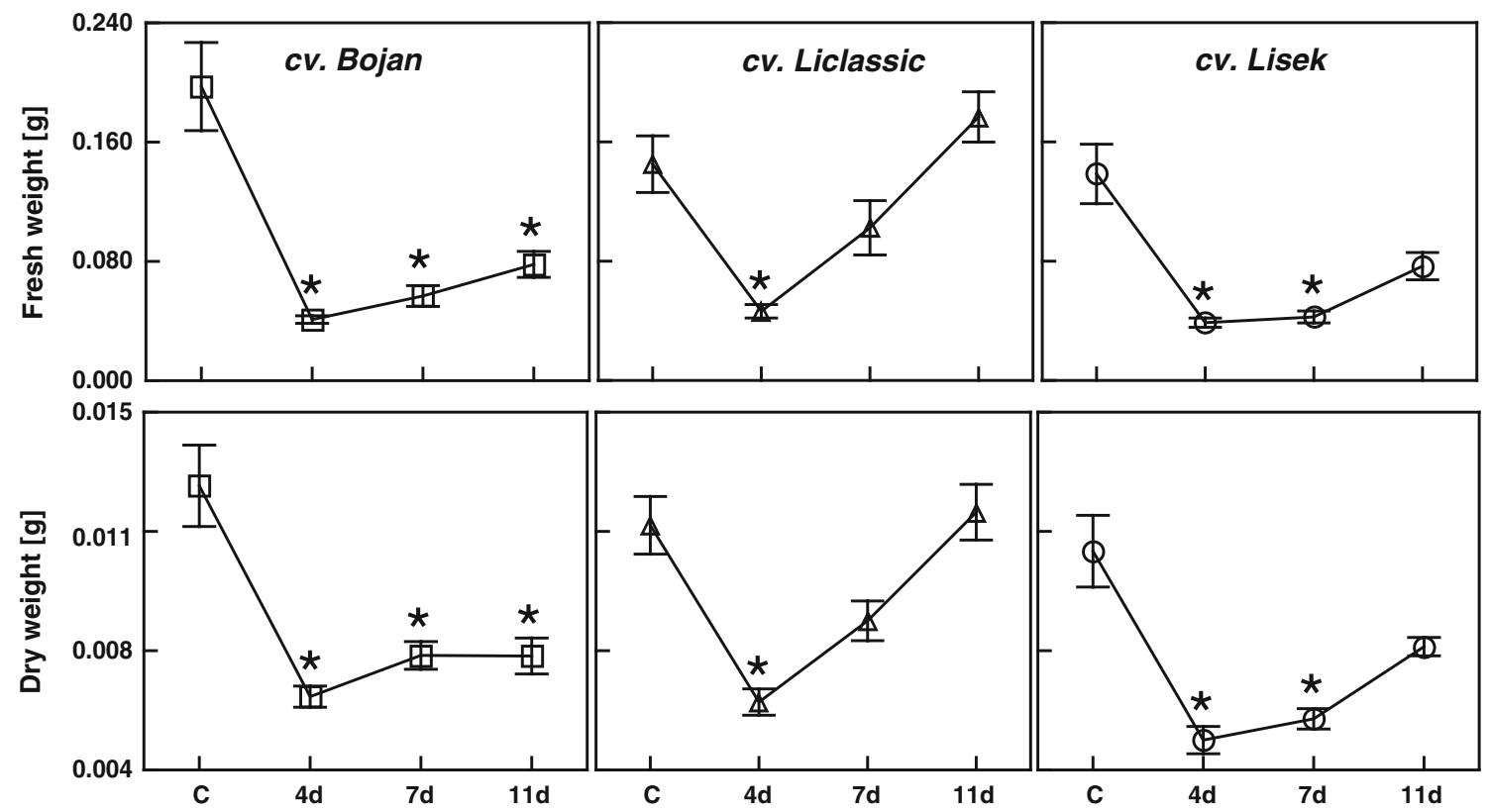

Fig. 5 Changes in fresh and dry weight for seedlings of winter rape cultivars ('Bojan', 'Liclassic', 'Lisek') observed for 4, 7 and 11 days after elicitation. Each point represents the mean \pm standard error.

4th day. In the 'Lisek' cultivar on the 4 and 7 th day, we noted a statistically significant decrease in fresh and dry weight compared to the control. For 'Liclassic' cultivar on the 7 and 11th day, a distinct trend in fresh and dry weight increments to the level of the control occurred. As shown in Fig. 6, the stem of 'Liclassic' seedlings was shorter but thicker on the medium with the elicitor. Similarly, cotyledons of this variety were larger in comparison to the control seedlings.

In all tested cultivars of oilseed winter rape during growth on a medium with a fungal elicitor, a distinct (compared to control) reduction in the length of the stems, the roots and the entire length of the seedlings was observed (Figs. 6, 7).
$C$ represents the mean for total measurements performed in parallel for 4,7 and 11 days on non-infected plants. $* P<0.05$ vs. control, Student's $t$ test

Relationship between the parameters of plant productivity and the level of chlorophyll, carotenoids and phenolics

Only in the case of the 'Liclassic' cultivar, for most of the measured parameters of chlorophyll fluorescence, we obtained a statistically significant correlation with regard to the level of carotenoids (Fig. 8a-d). The highest levels of carotenoids in this cultivar was observed on the 11th day of elicitation, as they correlated with the highest values of $F_{\mathrm{v}}{ }^{\prime}$ / $F_{\mathrm{m}}{ }^{\prime}, \Phi_{\mathrm{PSII}}, q_{\mathrm{P}}$ and $q_{\mathrm{N}}$. In the 'Lisek' cultivar such a relationship was found only for $F_{\mathrm{v}}{ }^{\prime} / F_{\mathrm{m}}{ }^{\prime}$ (Fig. 9a), while for the 'Bojan' cultivar, no statistically significant correlation was obtained. Moreover, for 'Liclassic', the $F_{\mathrm{v}} / F_{\mathrm{m}}$ parameter 


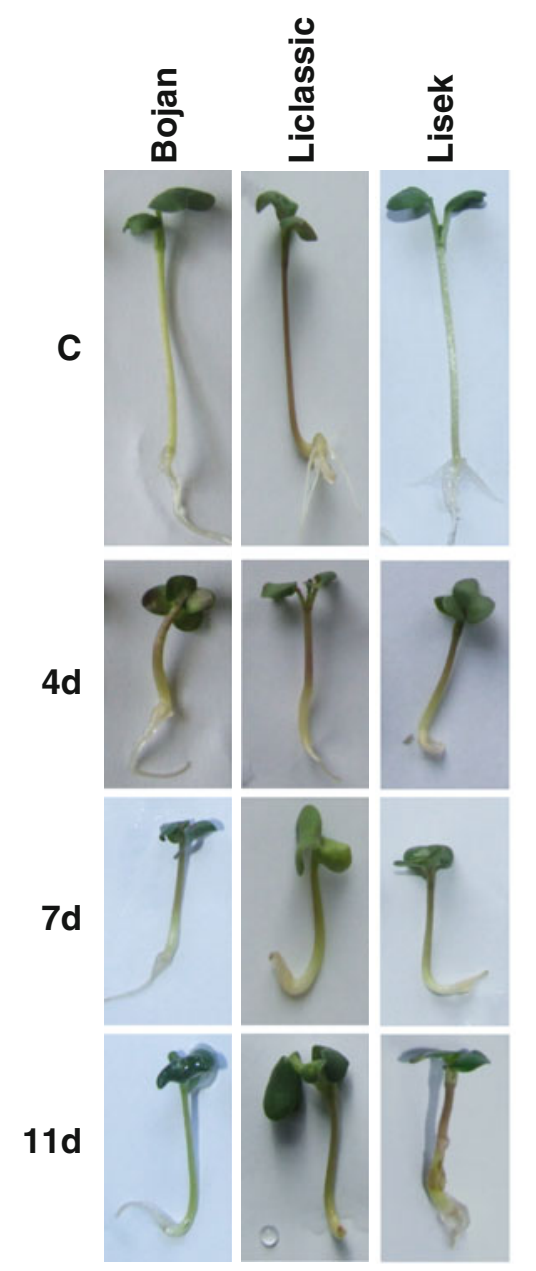

Fig. 6 Changes in morphological traits for seedlings of winter rape cultivars ('Bojan', 'Liclassic', 'Lisek') observed for 4, 7 and 11 days after elicitation

positively correlated with the chlorophyll content (Fig. 9b), while the phenolic content correlated with values of quantum efficiency of PSII in 'Bojan' (Fig. 9c). In this last case, the highest level of phenolic compounds was observed on the 11th day of elicitation and correlated with the highest values of $\Phi_{\text {PSII }}$.

Only in the 'Lisek' cultivar, was a statistically significant correlation between chlorophyll content and seedlings fresh/dry matter and seedlings length determined (Fig. 10).

\section{Discussion}

The chlorophyll fluorescence imaging method enabled detection of differences in the responses of the photosynthetic apparatus of oilseed winter rape to $L$. maculans $/ L$. biglobosa phytotoxins (Figs. 1, 2). In experiments on biotic stress, it was shown that fungi pathogens increase the pool of ROS in a plant cell (Herbette et al. 2003; Kuźniak and Skłodowska 2005; Torres et al. 2006), which may also damage the thylakoid membranes leading to impairment of the structure and function of the photosystems (Muhlenbock et al. 2008; Kangasjärvi et al. 2012). Scharte et al. (2005) showed that leaves of tobacco infected with Phytophthora nicotianae exhibited disturbances in photosynthetic electron transfer and low photosynthetic activity during the first hours after the inoculation.

Only in the case of the 'Liclassic' cultivar, there were statistically significant correlations between the level of carotenoids and the majority of chlorophyll fluorescence parameters: $F_{\mathrm{v}}{ }^{\prime} / F_{\mathrm{m}}{ }^{\prime}, \Phi_{\mathrm{PSII}}, q_{\mathrm{P}}$ and $q_{\mathrm{N}}$ (Fig. 8). Also for this cultivar on the 11th day of elicitation, a significantly higher activity of photosynthetic apparatus was observed in comparison to the control (Fig. 1), which corresponded to the significantly higher, than in the control, content of the carotenoids (Fig. 3). The participation of carotenoids in the neutralization of free radicals has been reported (Woodall et al. 1997). Study of Tian et al. (2007) confirmed that high level of carotenoids help in combating environmental stresses. In their experiment, the mutant of Deinococcus radiodurans, which failed to synthesize carotenoids, was more sensitive to ROS than the wild type. Only for the 'Bojan' cultivar, which was characterized by a decrease in levels of carotenoids during elicitation, we noticed, on the 11th day of elicitation, a very distinct (compared to the control and other cultivars) decrease in photosynthetic apparatus activity (Figs. 1, 2). Moreover, only for this cultivar, on the basis of changes in $R_{\mathrm{Fd}}$ values (Fig. 2), it is possible to suggest considerable disturbances in $\mathrm{CO}_{2}$ fixation, which also resulted in inhibition of seedlings dry weight increment (Fig. 5).

Accompanying the increase in carotenoid content in a 'Liclassic' cultivar, there was an increase in chlorophyll content on the 11th day of elicitation (Fig. 3), which could be an additional factor that had a positive influence on the increase in the maximum quantum yield of photosystem II (Fig. 9b). Rusjan et al. (2012) showed a decrease in the content of chlorophyll and carotenoids in sensitive grape cultivar in the course of pathogenesis. Similar results concerning biotic stress have been observed in other experiments (Petit et al. 2006; Gutha et al. 2010). The decline in chlorophyll content may be associated with the process of detoxification of compounds derived from a fungal pathogen. The participation of chlorophyll degradation products in the mechanisms of phytotoxin neutralization was found during plants ageing (Guo and Gan 2005). 

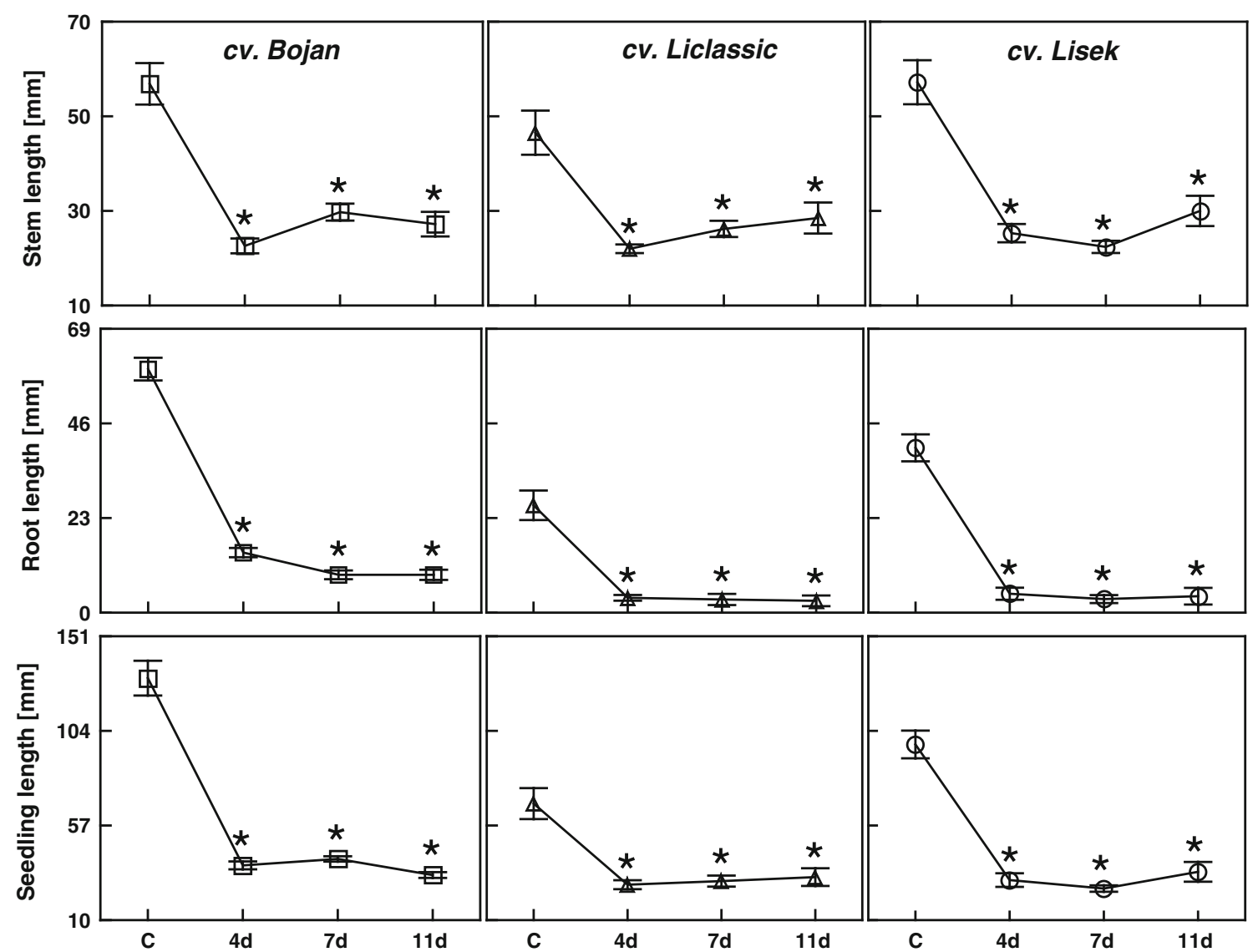

Fig. 7 Changes in stem, root and seedling length of winter rape cultivars ('Bojan', 'Liclassic', 'Lisek') observed for 4, 7 and 11 days after elicitation. Each point represents the mean \pm standard error.

Simultaneously, changes in the activity of photosynthetic apparatus in seedlings growing on the medium with a fungal elicitor were accompanied by changes in the phenolic content (Fig. 4). In the case of a 'Liclassic' cultivar, a gradual increase in the content of phenolic compounds (Fig. 4) under elicitation could also have an impact on adaptation of the photosynthetic apparatus. Phenolic pathway activation is a common response to various stress factors (Dixon and Pavia 1995). It has been proved that phenolics are involved in defence mechanisms associated with the infection of pathogenic microorganisms. Many of these substances were described as phytoalexins or scavengers of reactive oxygen species. The role of phenolics in plant defence under fungal infection has been confirmed in some studies (Płażek et al. 2003, 2005; Pourcel et al. 2007). Shadle et al. (2003) have been found that tobacco plants with high level of phenylpropanoids markedly reduced the susceptibility to infection with the fungal pathogen Cercospora nicotianae.
$C$ represents the mean for total measurements performed in parallel for 4,7 and 11 days on non-infected plants. $* P<0.05$ vs. control, Student's $t$ test

In the case of 'Liclassic', the efficient adaptation of the photosynthetic apparatus to elicitation with fungal toxins also indicates the gradual increase in dry weight up to the level of the control plants, which was observed only in the case of this cultivar (Fig. 5). Reduction of dry and fresh weight in the case of 'Liclassic' on the 4th day of seedlings growth can be recognized as adaptation mechanism. In our opinion, for 'Liclassic', the observed decrease in dry and fresh weight (4th day) is probably connected to carbohydrate utilization in the production of secondary metabolites (phenolics) that are involved in defence mechanisms at the cost of growth reduction. The visible and negative effect of pathogens on rape seedlings was related to morphological traits such as seedling length, stem length and root length (Fig. 7). However, the mentioned traits were not sufficiently differentiated to be useful for estimation of the sensitivity of the cultivar to Phoma lingam phytotoxins.

In conclusion, on the basis of the obtained results, we can surmise that the 'Liclassic' cultivar is characterized by 


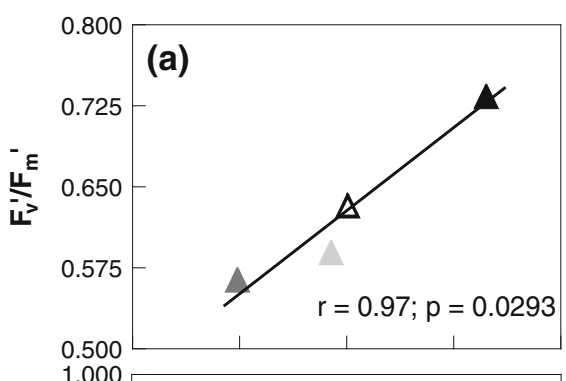

(b)

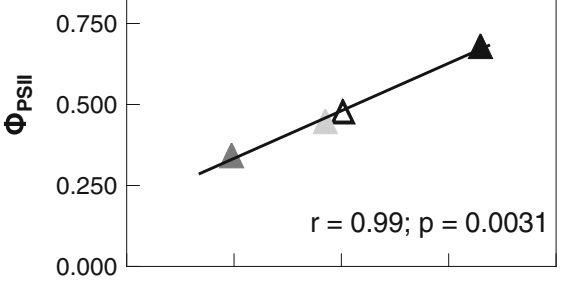

(c)
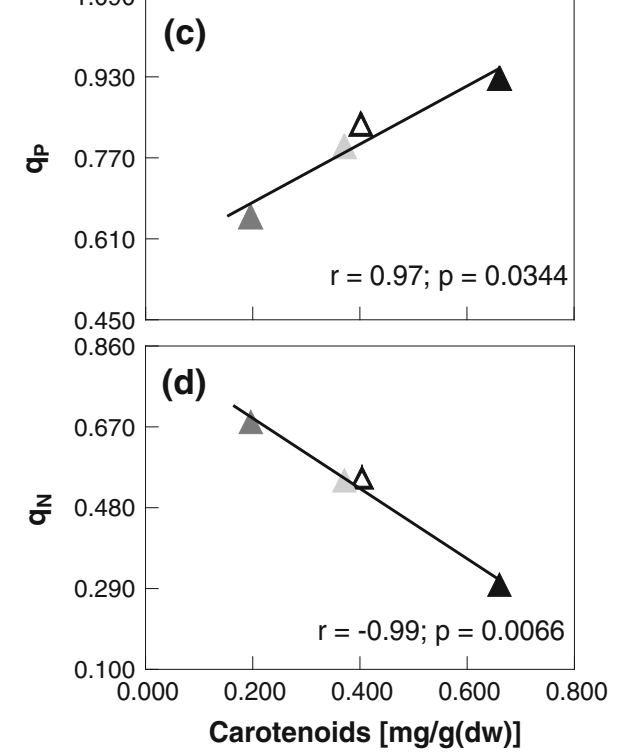

Fig. 8 Correlations between $F_{\mathrm{v}}{ }^{\prime} / F_{\mathrm{m}}{ }^{\prime}$ (the efficiency of excitation transfer to open PSII centres) (a), $\Phi_{\text {PSII }}$ (PSII quantum efficiency) (b), $q_{\mathrm{P}}$ (photochemical quenching coefficient) (c), $q_{\mathrm{N}}$ (non-photochemical quenching coefficient) (d) and carotenoid levels for seedlings of 'Liclassic' cultivar. Control white triangle; 4 days after elicitation light grey triangle, 7 days after elicitation grey triangle, 11 days after elicitation black triangle. Lines represent linear adjustment

the most efficient photosynthetic apparatus under elicitation by Phoma lingam toxins. It should be pointed that solely the photosynthetic apparatus of this variety was reversibly affected during elicitation. This was related to the induction of biochemical defence mechanisms which enabled an effective photosynthetic apparatus adaptation. A significant element of the efficient adaptation of photosynthetic apparatus in 'Liclassic' was an increase in the
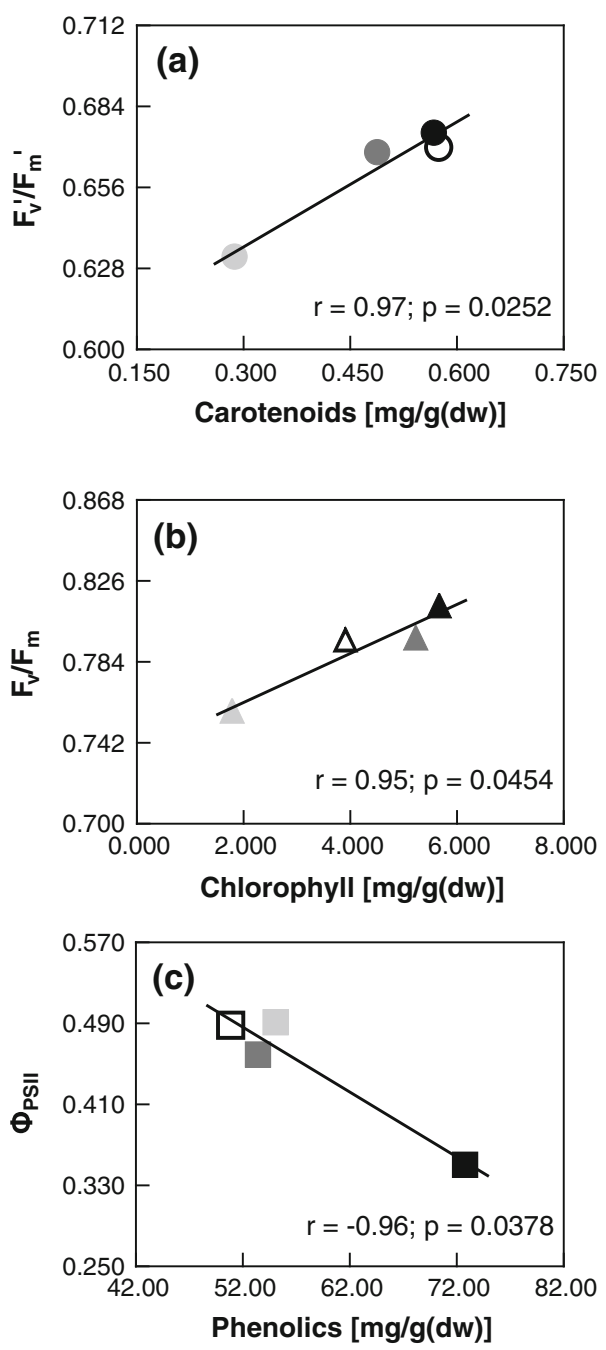

Fig. 9 Correlations between $F_{\mathrm{v}}{ }^{\prime} / F_{\mathrm{m}}{ }^{\prime}$ (the efficiency of excitation transfer to open PSII centres) and carotenoid level for Lisek (a), $F_{\mathrm{v}} /$ $F_{\mathrm{m}}$ (the maximum photochemical efficiency) and chlorophyll level for Liclassic (b), $\Phi_{\text {PSII }}$ (PSII quantum efficiency) and total pool of phenolic content for Bojan (c). Control white points; 4 days after elicitation light grey points, 7 days after elicitation grey points, 11 days after elicitation black points. Lines represent linear adjustment

content of phenolic compounds, which due to the chemical structure can act as free radical scavengers. Another observed effect was an increase in the content of chlorophyll and carotenoids, which consequently led to the increased activity of the photosynthetic apparatus. Moreover, for 'Liclassic', the observed increase in carotenoid content seems to be a significant biochemical factor which can raise the efficiency of the photosynthetic apparatus under elicitation by Phoma lingam toxins. However, to confirm unambiguously, it is necessary to carry out further 

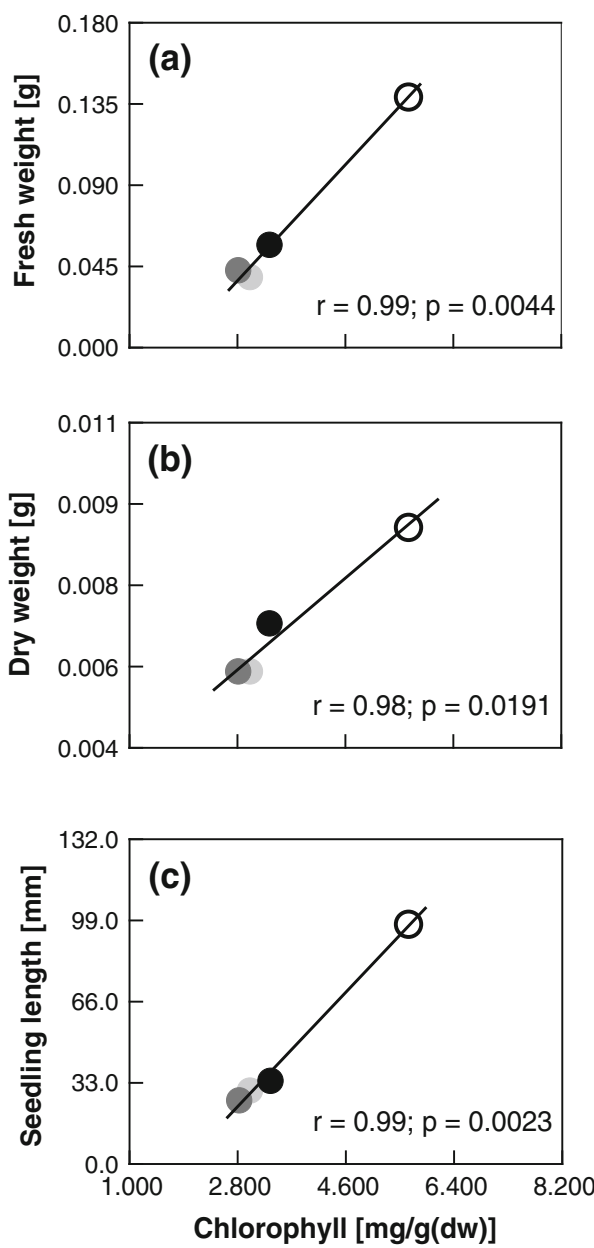

Fig. 10 Correlations between fresh weight (a), dry weight (b), seedling length (c) and chlorophyll level for seedlings of 'Lisek' cultivar. Control white circles; 4 days after elicitation light grey circles, 7 days after elicitation grey circles, 11 days after elicitation black circles. Lines represent linear adjustment

studies with a microscopy (cross sections) visualization of the pathogen spread in plants and with larger number of oilseed winter rape cultivars with different levels of resistance to Phoma lingam.

Author contribution Katarzyna Hura carried out the experiments, data analysis and the prepared the manuscript. Tomasz Hura and Maciej Grzesiak participated in the biochemical analysis. All authors read and approved the final manuscript.

Acknowledgments The authors would like to thank Assoc. Prof. Małgorzata Jędryczka from the Institute of Plant Genetics PAS in Poznan for providing the isolate (Raw4) of the Phoma lingam.

Open Access This article is distributed under the terms of the Creative Commons Attribution License which permits any use, distribution, and reproduction in any medium, provided the original author(s) and the source are credited.

\section{References}

Baker NR, Rosenqvist E (2004) Applications of chlorophyll fluorescence can improve crop production strategies: an examination of future possibilities. J Exp Bot 55:1607-1621

Blokhina O, Virolainen E, Fagerstedt KV (2003) Antioxidants, oxidative damage and oxygen deprivation stress: a review. Ann Bot 91:179-194

Brun H, Chevre AM, Fitt BDL, Powers S, Besnard AL, Ermel M, Huteau V, Marquer B, Eber F, Renard M, Andrivon D (2010) Quantitative resistance increases the durability of qualitative resistance to Leptosphaeria maculans in Brassica napus. New Phytol 185:285-299

Buschmann C, Lichtenthaler HK (1998) Principles and characteristics of multi-colour fluorescence imaging of plants. J Plant Physiol 152:297-314

Buschmann C, Langsdorf G, Lichtenthaler HK (2000) Imaging of the blue, green, and red fluorescence emission of plants: an overview. Photosynthetica 38:483-491

Dawidziuk A, Kaczmarek J, Podleśna A, Kasprzyk I, Jędryczka M (2012) Influence of meteorological parameters on Leptosphaeria maculans and L. biglobosa spore release in central and eastern Poland. Grana 51:240-248

De Ascensao ARFDC, Dubery IA (2003) Soluble and wall-bound phenolics and phenolic polymers in Musa acuminate roots exposed to elicitors from Fusarium oxysporum f.sp. cubense. Phytochemistry 63:679-686

Dixon RA, Pavia NL (1995) Stress-induced phenylpropanoid metabolism. Plant Cell 7:1085-1097

Fracheboud Y, Leipner J (2003) The application of chlorophyll fluorescence to study light, temperature and drought stress. In: De Ell JR, Tiovonen PMA (eds) Practical applications of chlorophyll fluorescence in plant biology. Kluwer Academic Publishers, Boston, pp 125-150

Gladders P, Musa TM (1980) Observations on the epidemiology of Leptosphaeria maculans stem canker in winter oilseed rape. Plant Pathol 29:28-37

Guo Y, Gan S (2005) Leaf senescence: signals, execution and regulation. Curr Top Dev Biol 71:92-95

Gutha LR, Casassa LF, Harbertson JF, Naidu RA (2010) Modulation of flavonoid biosynthetic pathway genes and anthocyanins due to virus infection in grapevine (Vitis vinifera $\mathrm{L}$.) leaves. BMC Plant Biol 10:187-205

Havaux M, Bonfils JP, Lütz C, Niyogi KK (2000) Photodamage of the photosynthetic apparatus and its dependence on the leaf developmental stage in the npql Arabidopsis mutant deficient in the xanthophyll cycle enzyme violaxanthin de-epoxidase. Plant Physiol 124:273-284

Herbette S, Lenne C, Tourvieille de Labrouhe D, Drevet JR, RoeckelDrevet P (2003) Transcripts of sunflower antioxidant scavengers of the SOD and GPX families accumulate differentially in response to downy mildew infection, phytohormones, reactive oxygen species, nitric oxide, protein kinase and phosphatase inhibitors. Physiol Plant 119:418-428

Hura T, Hura K, Grzesiak M (2010) Early stage de-etiolation increases the ferulic acid content in winter triticale seedlings under full sunlight conditions. J Photochem Photobiol B Biol 101:279-285

Jędryczka M, Starzycki M, Lewartowska E, Frencel I (1991) Studies of in vitro toxic effect of Phoma lingam (Tode ex Fr.) Desm. culture filtrate on winter oilseed rape (Brassica napus L.) haploid embryos. IOBC/WPRS Bull 14(6):196-204

Jędryczka M, Lewartowska E, Frencel I (1994) Properties of Phoma lingam (Tode ex fr.) Desm. isolates from Poland, pathogenicity characterization. Phytopathol Pol 7:71-79 
Jędryczka M, Rouxel T, Balesdent MH, Mendes Pereira E, Bertrandy J (1997) Molecular characterization of Polish Phoma lingam isolates. Cereal Res Commun 25:279-283

Jędryczka M, Irzykowski W, Jajor E, Korbas M (2010) Polymorphism of ten new minisatellite markers in subpopulations of phytopathogenic fungus Leptosphaeria maculans differing with metconazole treatment. J Plant Prot Res 50:103-110

Kachlicki P, Jędryczka M (1994) Properties of Phoma lingam (Tode ex fr.) Desm. isolates from Poland, secondary metabolites production. Phytopathol Pol 7:81-86

Kaczmarek J, Jędryczka M, Cools H, Fitt BDL, Lucas JA, LatundeDada AO (2012) Quantitative PCR analysis of abundance of airborne propagules of Leptosphaeria species in air samples from different regions of Poland. Aerobiologia 28:199-212

Kangasjärvi S, Neukermans J, Li S, Aro EM, Noctor G (2012) Photosynthesis, photorespiration, and light signalling in defence responses. J Exp Bot 63:1619-1636

Kuźniak E, Skłodowska M (2005) Fungal pathogen-induced changes in the antioxidant systems of leaf peroxisomes from infected tomato plants. Planta 222:192-200

Lichtenthaler HK, Wellburn RR (1983) Determination of total carotenoids and chlorophylls $\mathrm{a}$ and $\mathrm{b}$ of extracts in different solvents. Biochem Soc Trans 603:591-592

Muhlenbock P, Szechynska-Hebda M, Plaszczyca M, Baudo M, Mullineaux PM, Parker JE, Karpinska B, Karpinski S (2008) Chloroplast signaling and LESION SIMULATING DISEASE1 regulate cross talk between light acclimation and immunity in Arabidopsis. Plant Cell 20:2339-2356

Murashige T, Skoog F (1962) A revised medium for rapid growth and bioassay of tobacco tissue culture. Physiol Plant 15:473-497

Nedbal L, Soukupová J, Kaftan D, Whitmarsh J, Trtílek M (2000) Kinetic imaging of chlorophyll fluorescence using modulated light. Photosynth Res 66:3-12

Petit AN, Vaillant N, Boulay M, Clement C, Fontaine F (2006) Alteration of photosynthesis in grapevine affected by esca. Phytopathology 96:1060-1066

Płażek A, Hura K, Żur I (2003) Reaction of winter oilseed rape callus to different concentrations of elicitors: pectinase or chitosan. Acta Physiol Plant 25:83-89

Płażek A, Rapacz M, Hura K (2004) Relationship between quantum efficiency of PSII and cold-induced plant resistance to fungal pathogens. Acta Physiol Plant 26:141-148
Płażek A, Hura K, Żur I (2005) Influence of chitosan, pectinase and fungal metabolites on activation of phenylopropanoid pathway and antioxidant activity in oilseed rape callus. Acta Physiol Plant 27:95-102

Pourcel L, Routaboul JM, Cheynier V, Lepiniec L, Debeaujon I (2007) Flavonoid oxidation in plants: from biochemical properties to physiological functions. Trends Plant Sci 12:29-36

Rusjan D, Halbwirth H, Stich K, Mikulič-Petkovšek M, Veberič R (2012) Biochemical response of grapevine variety 'Chardonnay' (Vitis vinifera L.) to infection with grapevine yellows (Bois noir). Eur J Plant Pathol 134:231-237

Scharte J, Schön H, Weis E (2005) Photosynthesis and carbohydrate metabolism in tobacco leaves during an incompatible interaction with Phytophthora nicotianae. Plant Cell Environ 28:1421-1435

Shadle GL, Wesley SV, Korth KL, Chen F, Lamb C, Dixon RA (2003) Phenylpropanoid compounds and disease resistance in transgenic tobacco with altered expression of L-phenylalanine ammonia-lyase. Phytochemistry 64:153-161

Singleton VS, Rossi JA Jr (1965) Colorimetry of total phenolics with phosphomolybdic-phosphotungstic acid reagent. Am J Enol Viticult 16:144-157

Telfer A (2005) Too much light? How carotene protects the photosystem II reaction centre. Photochem Photobiol Sci 4:950-956

Tian B, Xu Z, Sun Z, Lin J, Hua Y (2007) Evaluation of the antioxidant effects of carotenoids from Deinococcus radiodurans through targeted mutagenesis, chemiluminescence, and DNA damage analyses. Biochim Biophys Acta 1770:902-911

Torres MA, Jones JD, Dangl JL (2006) Reactive oxygen species signalling in response to pathogens. Plant Physiol 141:373-378

West JS, Kharbanda PD, Barbetti MJ, Fitt BDL (2001) Epidemiology and management of Leptosphaeria maculans (phoma stem canker) on oilseed rape in Australia, Canada and Europe. Plant Pathol 50:10-27

Wingler A, Mareś M, Pourtau N (2004) Spatial patterns and metabolic regulation of photosynthetic parameters during leaf senescence. New Phytol 161:781-789

Woodall AA, Britton G, Jackson MJ (1997) Carotenoids and protection of phospholipids in solution or in liposomes against oxidation by peroxyl radicals: relationship between carotenoid structure and protective ability. Biochim Biophys Acta 1336:575-686 